\title{
Model experiments for selection on resistance to infection in mice and pigs
}

\author{
H. BUSCHMANN
}

Institut f. Med. Mikrobiologie

Veterinärstr. 13, D-8000 München 22

There are three main possibilities to find out if an immunological trait has a genetic background : studies in twins, the demonstration of line and breed differences, and the results of selection experiments. All three methodological approaches were used in our studies. In our studies with mice, cattle, and pig it could be shown that the rate of phagocytosis, the conglutinin titre of the blood serum in cattle, and the antibody response to sheep erythrocytes and DNP hapten are genetically determined. There is a dissociation between the genetic control of humoral and cell-mediated immune response. The results of selection experiments show that the host defence system has been optimally adapted to the environment by natural selection. Any artificial selection confers to the animals not only advantages but also serious disadvantages.

\section{Selection on antibody response in pigs}

\author{
J. MEYER, H. BUSSCHMANN and H. KRÄUSSLICH \\ Institut für Tierzucht $u$. Tierhygiene, Veterinärstr. 13 \\ D - 8000 München 22
}

A one-way selection experiment on antibody response in pigs is described. The only selection criterion is the immune response - anti hapten antibodies in the serum of growing pigs - after immunization with dinitrophenyl (DNP)-bovine-serum albumin.

The selection experiment is running in the $5^{\text {th }}$ generation. In the $4^{\text {th }}$ generation are 100 p. 100 responders in the selected line as compared to about 65 p. 100 non-responders in the basic population. In comparison to the basic population the mean response of the $4^{\text {th }}$ generation has increased about ninefold.

Within each generation there are half-sib groups fathered by one to three boars. Thus selection can be done almost exclusively in the females. The control of the correlated response of selection with regard to breeding for resistance against diseases is beginning now.

\section{Serum Immunogiobulin levels in cattle : genetic variation and relation to diseases}

\section{P. JENSEN *, P. MADSEN ** and N.E. JENSEN *}

* State Veterinary Serum Laboratory, Bülowsvej 27, 1870 Copenhagen V, Denmark ** National Institute of Animal Science, Rolighedsvej 25, 1958 Copenhagen V, Denmark

Concentrations of IgA, IgM, IgG-1, IgG-2, albumin and total protein were determined in sera from 56 unselected sire groups comprising 1221 first-lactation cows in 67 dairy herds. Infections of the limbs, mastitis, respiratory infections, and diseases altogether were 
registered and treated as all-or-none traits in genetics analyses. A significant sire effect was found for all serum traits except albumin, with heritability estimates between 0.1 and 0.2 . The disease characters showed heritability estimates between 0.04 and 0.08 . Immunoglobulin and total-protein concentrations seemed to have a negative genetic correlation to diseases.

\title{
Genetic polymorphisms of plasma $\alpha_{1}$-protease inhibitors in some domestic animals
}

\author{
R. KUMAR JUNETA and B. GAHNE \\ Department of Animal Breeding and Genetics, \\ Swedish University of Agricultural Sciences, S-750 07 Uppsala, Sweden
}

The genetic polymorphism and phenotypes of plasma $\alpha_{1}$-protease inhibitor $\left(\alpha_{1}-\mathrm{PI}\right)$ in horse, cattle, sheep, goat, pig, dog and mink were described in a brief review. In all these species, two $\alpha_{1}$-protease inhibitors (Pi-1 and Pi-2) were observed. Pi-1 showed inhibition for both trypsin and chymotrypsin while Pi-2 showed inhibition for only trypsin. In horse $6 \mathrm{Pi}-1$ and $5 \mathrm{Pi}-2$ alleles were observed. There was a very close genetic linkage between $\mathrm{Pi}-1$ and $\mathrm{Pi}-2$ loci in horse. The horse $\mathrm{Pi}-1$ and $\mathrm{Pi}-2$ fractions together correspond to the horse acidic prealbumin (Pr) fractions described earlier in literature.

In cattle, sheep and goat, polymorphism was observed for only Pi-2. Three alleles in cattle, three in sheep and two alleles in goat were observed.

In pig, the earlier described polymorphism pre-albumin $(\mathrm{Pa})$ was identified as $\alpha_{1}$-protease inhibitor. Two $\mathrm{Pa}$ alleles have been reported in pig.

In dog and mink, polymorphism was observed only for Pi-1. Three $\mathrm{Pi}-1$ alleles were observed in several breeds of dogs. In mink, the polymorphic post-albumin (Pa) described in literature, was identified as $\alpha_{1}$-protease inhibitor.

The $\alpha_{1}$-PI fractions in all these species are present in high concentration in plasma and thus could be visualised by general protein staining of gels after electrophoresis. The possible association of $\alpha_{1}-\mathrm{PI}$ phenotypes with respiratory and inflammatory diseases in domestic animals was also briefly discussed.

\section{Immune response to some $E$. coli antigens in swine}

\section{EDFORS-LILJA *, B. GAHNE *, B. MOREIN ** and H. PETERSSON *}

* Dep. of Animal Breeding and Genetics, Swedish University of Agricultural Science, S-750 07 Uppsala, Sweden

** National Veterinary Institute, S-104 05 Stockholm, Present address :

Dep. of Virology, Swedish University of Agricultural Science, Box 585

S-751 23 Uppsala, Sweden

The humoral immune responses to two $E$. coli antigens, K88 and 0149 , were studied in 60 pigs after 9 sires and from 19 litters. One animal per litter was in addition kept as a control. The animals were immunized subcutaneously with a whole cell suspension of $E$. coli at the age of approximately 10 weeks. Ten of the animals were given a second immunization 3 weeks after the first one. Blood samples were taken immediately before immunization, 1 and 2 weeks post-injection. The total amount of specific antibodies in serum to K88 and 0149 antigen were analysed by ELISA technique. A significant increase in antibody titers was obtained after immunization, although a pronounced individual variation was seen. The animals were given a constant dose of the suspension without regard to 